\title{
Projetos educativos, crianças negras e socialização: quais diálogos são possíveis?
}

Educational projects, black children and socialization: which dialogues are possible?

\section{Luciana Fontes Pessôa \\ (Orientadora) \\ pessoalf@gmail.com}

Professora Adjunta e Diretora do

Departamento de Psicologia da Pontifícia

Universidade Católica do Rio de Janeiro

\section{Claudina Damasceno Ozório cdozorio@gmail.com}

Doutoranda em Psicologia Clínica no Departamento de Psicologia da Puc-Rio Bolsista CAPES/PROSUC1

\begin{abstract}
Resumo pensados quando se trata de crianças negras.

Palavras-chave: família; escola; educação; projetos inclusivos.
\end{abstract}

O presente artigo propõe-se pensar sobre os atravessamentos da cor de pele no processo de socialização. Alguns estudos que discorrem sobre a forma como a família e a escola lidam com as relações étnico-raciais são apresentados. Constata-se a permanência do silêncio em torno da temática racial. Questiona-se, então, como projetos educativos mais inclusivos podem ser

\begin{abstract}
This article proposes to think about the overlaps of skin color in the socialization process. Some studies that discuss the way how the family and the school deal with ethnic-racial relations are presented. Thus, it is possible to verify the perpetuation of silence around this theme. Hence, there's an investigation of how more inclusive educational projects can be thought of when it comes to black children.
\end{abstract}

Keywords: family; school; education. 
OZÓRIO, Claudina Damasceno; PESSÔA, Luciana Fontes. Projetos educativos, crianças negras e socialização: quais diálogos são possíveis?

\section{Introdução}

Em 2020 fomos acometidos pela pandemia do coronavírus (Covid-19), que nos levou ao isolamento devido ao modo de transmissão e à letalidade do vírus. Esse contexto levou ao confinamento doméstico, obrigando as famílias a uma nova adaptação em suas relações. Assim como as famílias, a escola também precisou se adequar para que, dentro das possibilidades existentes, conseguisse manter minimamente um cronograma escolar. Ainda não é possível mensurar quais serão os resultados desse confinamento em longo prazo, especialmente nas relações familiares. Porém, alguns adventos sociais nos atravessaram de forma contundente, como as violências raciais reais, as mortes de pessoas negras sendo repercutidas na mídia, e as simbólicas, como ataques racistas via internet. Com isso, as discussões sobre racismo se tornaram pauta em diversas áreas da sociedade, adentrando o ambiente da família e da escola, exigindo a construção de espaços para diálogo nessas duas instâncias. Assim, reforça-se a necessidade de um olhar mais atento e direcionado para as relações raciais nos âmbitos familiar e escolar.

Desse modo, o presente estudo é parte de uma pesquisa mais ampla de doutoramento em psicologia clínica no departamento de Psicologia da PUC-Rio, ainda em processo de construção. O objetivo geral é investigar trajetórias de socialização de crianças negras em que se busca saber sobre as conexões invisíveis entre os familiares, que envolvem aspectos como a dinâmica familiar, as relações estabelecidas, a comunicação, a circulação dos afetos, dentre outros componentes relacionais entre os membros do grupo familiar. Para tanto, pretende-se entrevistar 30 sujeitos, sendo 15 mães (brancas ou negras) e 15 filhos/as (negros/as), ao longo da pesquisa de doutoramento. Serão utilizados como aportes teóricos para sustentar esta pesquisa estudos que discorrem sobre as especificidades das famílias negras e inter-raciais, a partir das análises presentes na Psicologia Clínica e Social, em diálogo com aspectos historiográficos, sociológicos e antropológicos que analisam esses grupos. Com isso, a pesquisa buscará compreender os aspectos e processos familiares, procurando maior entendimento a respeito dos fenômenos presentes nesses ambientes.

Esta pesquisa também lançará mão do modelo bioecológico do desenvolvimento humano de Urié Brofenbrenner (2011) como ferramenta para compreendermos o contexto em que esses indivíduos se desenvolvem, entendendo a criança em desenvolvimento como um sujeito biopsicossocial em um contexto que tende a sobredeterminá-la pela sua cor de pele. O autor enfatiza que o indivíduo em desenvolvimento está inserido em seu contexto, entrelaçado a alguns sistemas interligados, do mais próximo (microssistema) ao mais distante (exossistema), 
OZÓRIO, Claudina Damasceno; PESSÔA, Luciana Fontes. Projetos educativos, crianças negras e socialização: quais diálogos são possíveis?

perpassado pelo sistema intermediário (mesossistema), que operam dentro de um macrossistema que envolve crenças dominantes e ideologias. Pode-se supor, então, que tais crenças e ideologias estão fixadas na estrutura social e reverberam nas relações institucionais e interpessoais.

Estudos historiográficos como os dos autores Slenes (2011), Samara (1988), Freyre (2006) apresentam os modos de vida familiar dos negros ainda no período colonial e escravocrata. Em Casa Grande e Senzala, Freyre (2006) apresenta seus argumentos a respeito da miscigenação, trazendo pontos e contrapontos sobre a formação da sociedade brasileira. Seus estudos possibilitam o entendimento sobre a construção do imaginário social, vindo da intersecção-vivencial entre três grupos raciais fundamentais: o branco, o indígena e o negro. Os escritos do autor auxiliam na compreensão de algumas bases que estruturaram as ideias e crenças sobre o negro na sociedade brasileira.

Slenes enfatiza as relações de parentesco como importante elo para "a (re)criação de esperanças e recordações das pessoas: isto é, para a formação de memórias, projetos, visões de mundo e identidades" (2011, p.29). E o que seria da história e romance familiar sem a memória de seus parentes, ancestrais e rede de afetos? O autor busca resgatar a capacidade dos cativos em construírem uma vida conjugal, estabilidade familiar, parceria, projetos de vida em comum e valorização de laços de parentesco, consanguíneos e afins.

Samara (1988) apresenta uma visão mais abrangente dos estudos disponíveis sobre a família negra, em especial a família escrava, compostos por artigos e apresentações em congressos nos anos 1980. A autora enfatiza que havia uma visão deturpada e "estereotipada da promiscuidade do comportamento sexual do negro e do escravo" (Samara, 1988, p. 29), sendo o fio condutor dos trabalhos apresentados. Em relação à formação da família escrava, ela busca nos documentos históricos registros que possam relatar uniões estáveis e casamentos entre os cativos. De acordo com seus achados, "a família escrava antes vista como atípica, exceção à regra, emerge dos dados estatísticos extraídos dos documentos históricos mostrando que casamentos e uniões estáveis de cativos podiam ocorrer, apesar da violência a que estavam submetidos nesse sistema" (Samara, 1988, p. 30).

Os estudos desses pesquisadores nos introduzem no cenário social brasileiro mais amplo eem que a constituição familiar dos negros foi construída, sumariamente, dentro do regime escravista, um macrossistema social que inseriu os africanos em contexto brasileiro de subalternidade através da escravidão. Tal situação tem seus resquícios ainda na cena brasileira do séc. XXI e, consequentemente, possui reverberações nos moldes de como se relacionam as famílias negras e inter-raciais. Através das pesquisas desses autores é possível perceber que ao DIGNIDADE RE-VISTA | ISSN2525-698X| 2021 | V. VIII | N. 13 |Pacto Educativo Global: a busca por ressignificar a educação. Pastoral Universitária Anchieta PUC-RIO. 
OZÓRIO, Claudina Damasceno; PESSÔA, Luciana Fontes. Projetos educativos, crianças negras e socialização: quais diálogos são possíveis?

longo do período colonial-escravista criou-se a ideia, documentada inclusive, de que entre os cativos não haveria amor, família, nem esperanças e recordações, mas sim promiscuidade sexual, anomia, instabilidade familiar e patologia social. Tanto os estudos de Samara (1988), quanto as pesquisas de Slenes (2011) buscaram apresentar questionamentos quanto a esse modelo de família escrava, tentando romper com o imaginário social construído no período escravista sobre a família cativa, crença que se perpetuou ao longo das gerações.

Esses historiadores têm sido fontes importantes para a compreensão do macrossistema brasileiro no qual essas famílias estão inseridas. O retorno aos estudos sobre as famílias cativas e a formação da sociedade brasileira tem permitido apreender sobre a construção do imaginário social que atravessa o microssistema escolar e familiar dos negros. Sabe-se que, no Brasil, desde o período escravocrata até os dias atuais, há um histórico de desigualdades presentes na história da educação e escolarização de negros. Algumas leis foram criadas visando minimizar as desigualdades no âmbito educacional, tal qual a Lei 10.639/03, que torna obrigatório o ensino de Cultura Afro-brasileira, e a Lei 12.711/12, que abre as portas de acesso à educação superior. Essas leis entraram em vigor depois de muita pressão dos movimentos sociais e fazem parte de políticas públicas incentivadoras de uma política de valorização da diversidade e da história dos negros na sociedade. Porém, com os adventos da pandemia e com a paralisação das escolas e o seu modelo on-line, ainda não é possível saber quais resultados serão colhidos, especialmente tratando-se da educação para as relações raciais.

O resgate histórico tem auxiliado a construir a pesquisa para a tese, sendo fundamental para o entendimento dos modelos interativos, das crenças parentais, das metas de cuidado e dos projetos educativos, que são os eixos temáticos escolhidos para serem aprofundados nas entrevistas. Para o presente artigo, foi escolhido o eixo temático que discorre sobre os projetos educativos dos pais para as crianças negras, na tentativa de apresentar, ainda que de forma limitada, alguns estudos sobre família, educação e relações raciais, sendo esse último um dos principais pilares constituintes da sociedade brasileira. Pretende-se, então, apresentar um breve estudo em relação ao conteúdo teórico sobre socialização e projetos educativos das famílias negras e inter-raciais para os seus filhos(as) negros, enfatizando também o lugar da escola.

Com base nisso, o presente trabalho não pôde esquivar-se de abordar os estudos sobre os atravessamentos da cor nas famílias negras e na escola, questionando sobre a existência de diálogos possíveis. Assim, propõe-se trazer algumas reflexões sobre o contexto no qual as crianças negras se desenvolvem, pensando sobre como as relações raciais são vivenciadas no processo de socialização. Nesse contexto em que os projetos educativos se estabelecem, buscase, então, saber se as questões relacionadas à raça, como por exemplo, identidade, racismo, DIGNIDADE RE-VISTA | ISSN2525-698X| 2021 | V. VIII | N. 13 |Pacto Educativo Global: a busca por ressignificar a educação. Pastoral Universitária Anchieta PUC-RIO. 
OZÓRIO, Claudina Damasceno; PESSÔA, Luciana Fontes. Projetos educativos, crianças negras e socialização: quais diálogos são possíveis?

discriminação e preconceito, são levadas em consideração quando se trata dos projetos para as crianças negras, ou se predomina o silêncio sobre essas questões.

\section{Família, escola e os atravessamentos da cor de pele na socialização}

A família é considerada o ambiente de socialização primário do indivíduo desde o seu nascimento. Ela é a principal responsável por inseri-lo na trajetória social secundária, ou seja, na escola, na sociedade e nas demais instituições (Berger; Luckman, 1976). As relações estabelecidas entre os familiares podem servir como referência para as demais relações, posto que a família é o primeiro ecossistema do indivíduo, na dimensão micro.

O núcleo familiar pode ser considerado o primeiro grupo de socialização em que as crenças, os valores e o modo de vida se estabelecem e são compartilhados entre seus membros. Porém, é preciso olhar para o desenvolvimento humano através de uma perspectiva sociocultural, evolucionista e interacionista, considerando o papel do contexto (Seidl-deMoura; Mendes; Pessôa, 2009).

Nas famílias negras e inter-raciais, além desse processo de socialização há a necessidade de se observar os atravessamentos do racismo, discriminação e preconceito que perpassam o desenvolvimento da criança, especialmente quando se trata da inserção na trajetória social secundária. Porém, o próprio ambiente familiar pode ser um lugar de reprodução da lógica de violência racial presente no macrossistema social, conforme estudos de Schucman e Gonçalves (2017) sobre os impactos que a vivência do racismo têm na subjetividade dos indivíduos e as formas com que essas experiências interferem no processo de construção da identidade do sujeito, em sua autoimagem e na estima por si mesmo. Ademais, a cultura faz parte do macrossistema em que a família e a criança estão inseridas.

Desse modo, sistemas de representações e significações estão condicionados a uma lógica que compõe o social e orienta o viver em sociedade, sendo as formas de vida social parte dos sistemas de representação. Para Nogueira, "disso resulta que a vida coletiva, assim como a vida psíquica dos indivíduos, se faz de representações, ou seja, de figurações mentais" (2008, p. 41). Segundo a autora,

quando estabelecidos os sistemas de representação, sua lógica passa a ser introjetada, pela educação, nos indivíduos, de maneira a estabelecer, nestes, semelhanças essenciais que a vida no coletivo presume e que constitui a garantia de homogeneidade para o sistema social: é o que garante o processo de socialização dos indivíduos (Nogueira, 1998, p. 41).

DIGNIDADE RE-VISTA | ISSN2525-698X| 2021 | V. VIII | N. 13 |Pacto Educativo Global: a busca por ressignificar a educação. Pastoral Universitária Anchieta PUC-RIO. 
OZÓRIO, Claudina Damasceno; PESSÔA, Luciana Fontes. Projetos educativos, crianças negras e socialização: quais diálogos são possíveis?

É nessa cultura, com suas representações, classificações e significações, que a criança negra se desenvolverá, sendo a escola um dos ambientes que faz parte da trajetória secundária da criança. Nessa perspectiva, a discussão sobre as relações étnico-raciais no ambiente familiar e escolar é de suma importância para uma educação mais igualitária e inclusiva, sendo necessária, inclusive, que aconteça em âmbito nacional.

De acordo com Cavalleiro, é "uma discussão impreterível na medida em que o sistema de ensino mostra-se inadequado para o segmento negro da população" (1999, p. 39). A autora defende que tal discussão possibilitará dirimir as desigualdades raciais e promover um projeto novo de educação, possibilitando a inserção social. De acordo com ela, a criança em fase préescolar ainda não possui autonomia o suficiente para aceitar ou negar o ensino/aprendizado, sendo indefesa quanto aos estereótipos e preconceitos direcionados a ela. Desse modo, tanto os membros familiares, especialmente os cuidadores, quanto a escola, especialmente os professores, funcionam como mediadores do processo de socialização no ambiente em que a criança está inserida. Ambos os espaços precisam adotar uma postura que busque construir modos de produção de subjetividades racializadas e proporcionem o florescimento da consciência crítica, sabendo-se que o contexto encontrado está imerso em violência e opressão, conforme enfatiza Pinho (2019). O antropólogo apresenta sua experiência em pesquisa etnográfica em uma escola pública de ensino fundamental no interior da Bahia.

A partir de interconexões teóricas e metodológicas, ele propõe refletir sobre a sua prática localizada, que consiste em trazer o mundo dos alunos para a realidade escolar, na tentativa de criar uma zona comum entre eles. Segundo o autor, "o que podemos oferecer ou devolver a esses jovens, acredito, é a própria oportunidade para o florescimento da consciência crítica que esses desenvolvimentos passam a exercer por meio dessa atividade eminentemente reflexiva" (Pinho, 2019, p. 358).

Dessa forma, além de mediadores, os responsáveis pela educação da criança precisam construir ferramentas adequadas para a construção de práticas educativas disruptivas, em contraste à realidade social estabelecida. No entanto, essa realidade social precisa ser percebida para ser confrontada, tanto na família quanto na escola.

Alguns estudos sobre famílias negras e inter-raciais têm servido de bússola importante para pensar sobre o ambiente primário do indivíduo em desenvolvimento (Chagas, 2014; Schucman, 2018), jogando luz sobre a dinâmica do afeto atravessada pela cor de pele. Os estudos sociológicos de Hordge-Freeman (2019) sobre características raciais, estigma e socialização em famílias negras brasileiras auxiliam a pensar sobre o poder das hierarquias raciais em adentrar os espaços de intimidade. Sua pesquisa apresenta como se dá a circulação DIGNIDADE RE-VISTA | ISSN2525-698X| 2021 | V. VIII | N. 13 |Pacto Educativo Global: a busca por ressignificar a educação. Pastoral Universitária Anchieta PUC-RIO. 
de afetos no âmbito das famílias negras pesquisadas, apontando as ambiguidades e complexidades dos laços familiares, em que a cor de pele é um fator moderador para a liberação de afetos mais positivos ou mais negativos.

Assim, a trajetória de socialização envolve os diversos contextos em que a criança está inserida: família, escola, grupos de iguais, vizinhança e a sociedade em geral. As pesquisas que tratam sobre socialização e relações raciais com famílias negras (Barbosa, 1983; Cavalleiro, 1999) correlacionadas com outros estudos sobre modelo de socialização e desenvolvimento humano (Seidl-de-Moura; Mendes; Pessôa, 2009; Keller, 1998) têm sido fontes importantes para apreender como as crianças negras interagem e como são recebidas nesses espaços, especialmente no que tange ao ambiente familiar e à escola, além de fornecer dados importantes sobre como os pais e os professores lidam com as questões advindas das relações raciais.

Sobre o papel do núcleo familiar na formação da identidade e na proteção do indivíduo em desenvolvimento, Barbosa (1983) discorre sobre como as famílias negras preparam seus filhos para o enfrentamento de situações racistas e também em relação aos brancos, observando se utilizam "mecanismos especiais" nessa jornada. De acordo com a autora,

esse processo é uma das funções mais importantes da família, de modo geral, e da família negra de modo especial: esta, além de preparar as crianças para desempenharem os papéis exigidos pela sociedade, terá que prepará-las para desempenharem esses papéis em condições especiais, pois aqui a criança terá que "saber ser uma criança negra vivendo entre brancos e negros". (Barbosa, 1983, p. 51)

Em busca de compreender o processo de socialização na educação infantil, Cavalleiro (1999) realizou uma pesquisa de campo, através de observação sistêmica, visando o entendimento das relações étnicas e interpessoais, estabelecidas no ambiente pré-escolar, no ambiente familiar e entre professores e alunos. De acordo com a autora, tanto na família quanto na escola há um silêncio relacionado ao racismo, preconceito e discriminação contra negros, promovendo oportunidades diferentes para brancos e negros, especialmente no âmbito escolar. Segundo a autora,

no que tange ao espaço escolar, as crianças estão tendo infinitas possibilidades para a interiorização de comportamentos e atitudes preconceituosas e discriminatórias contra os negros (...) O silêncio que atravessa os conflitos étnicos na sociedade é o mesmo silêncio que sustenta o preconceito e a discriminação no interior da escola. Nela, de modo silencioso ocorrem situações que podem influenciar a socialização das crianças, mostrando-lhes, infelizmente, diferentes lugares sociais para pessoas brancas e negras. A escola oferece aos alunos, brancos e negros, oportunidades diferentes para se sentirem aceitos, respeitados e positivamente participantes da vida escolar e

DIGNIDADE RE-VISTA | ISSN2525-698X| 2021 | V. VIII | N. 13 |Pacto Educativo Global: a busca por ressignificar a educação. Pastoral Universitária Anchieta PUC-RIO. 
da sociedade brasileira. A origem étnica condiciona um tratamento diferenciado na escola. (Cavalleiro, 1999, p. 47)

No caso das famílias estudadas, embora os adultos e os jovens estejam preparando os filhos para a vida social, é possível identificar que ainda persistem lacunas de pertencimento e identificação racial dentre os próprios grupos, que desconsideram o caráter multiétnico presente na população brasileira. A pesquisa de Cavalleiro (1999) vai ao encontro dos estudos de Schucman e Gonçalves (2017) quando aborda as possíveis consequências do tratamento que as crianças negras recebem, tanto no âmbito familiar quanto no escolar, marcad por constantes humilhações e rejeição, contribuindo para o condicionamento dos negros ao fracasso, à submissão e ao medo, dificultando a construção de uma identidade positiva. Cavalleiro (1999) apresenta ainda outro fator agravante presente nas relações étnico-raciais que é o lugar da criança branca. Esta, simultaneamente, é:

levada a cristalizar um sentimento de superioridade, visto que, diariamente, recebe provas fartas dessa premissa. A escola, assim, atua na difusão do preconceito e da discriminação. Tais práticas, embora não se iniciem na escola, contam com o seu reforço, a partir das relações diárias, na difusão de valores, crenças, comportamentos e atitudes de hostilidade em relação ao grupo negro. (Cavalleiro, 1999, p. 47)

Abramowicz e Oliveira propuseram "analisar a especificidade da socialização das crianças negras nas instituições de cuidado e educação à pequena infância" (2012, p. 47), além de propor uma reflexão sobre educação na infância. Segundo elas, é preciso levar em consideração a heterogeneidade presente na ideia de singularidade da infância na sociedade brasileira, e apresentam argumentos que confirmam que a socialização da criança negra na escola é diferente da vivenciada pela criança branca.

Em estudo de Wagner et al. (2012) sobre a perspectiva de pais e mães em relação aos projetos para os filhos e as estratégias de socialização, a educação de qualidade parece ser um valor central nos projetos educativos dos pais para os filhos. Um dos pontos considerados nesta pesquisa aponta para a relevância do fator classe, e não o fator racial dentro da análise, considerando o recorte social, marcado pelos níveis socioeconômico-cultural médios. Os pais buscam proporcionar aos filhos boa educação com escola de qualidade, cursos de línguas estrangeiras, intercâmbios no exterior, entre outros recursos, de modo que possam ter realização profissional no futuro. Do mesmo modo, investem no conforto dos filhos e no desenvolvimento de habilidades psicossociais diferenciadas. Supõe-se, então, que as preocupações presentes na pesquisa dizem respeito a um grupo racial não negro, pois há um silêncio em relação às questões 
OZÓRIO, Claudina Damasceno; PESSÔA, Luciana Fontes. Projetos educativos, crianças negras e socialização: quais diálogos são possíveis?

raciais ou, talvez, persista a mesma lacuna de pertencimento e identificação presente nas famílias estudadas por Cavalleiro (1999).

Porém, chamou-nos a atenção o fato de a mesma temática "projetos educativos" seguir caminhos distintos quanto ao acesso à educação formal quando o tema é racializado, ou seja, quando o fator racial atravessa a construção dos projetos. No caso de crianças negras, as discussões giram em torno de como recebê-las no ambiente escolar de modo a não ofertar as violências raciais sistêmicas, o que atravessa o projeto pedagógico da escola e os modos de tratamento, especialmente dos professores, direcionados à criança.

Tais pesquisas corroboram os escritos de Fanon (2008). Em Pele negra, máscaras brancas, o autor discorre sobre as questões que atravessam o corpo preto em uma sociedade que funciona com base em moldes brancos, apresentando as barreiras de liberdade para um negro em sociedades racistas e coloniais. Segundo ele, uma criança branca normal, nascida em uma família branca normal, tornar-se-á um adulto normal no mundo social que o cerca, pois, as normas e as regras do mundo são similares às que circulam em seu ambiente familiar. Porém, uma criança negra normal, nascida em uma família negra normal, tornar-se-á anormal ao primeiro contato com o mundo externo, pois as normas e regras estabelecidas socialmente são dissonantes com a sua realidade.

Desse modo, pode-se correlacionar a cor de pele como um fator que direciona os afetos ao longo do processo de socialização das crianças e ao mesmo tempo, apresenta um silêncio em torno dos "problemas raciais-relacionais", ocasionados pelo tom de pele. Assim, a depender do grupo racial ao qual pertence, ela terá o tratamento moderado pelo racismo, discriminação e preconceito, podendo inclusive inseri-la em um lugar de patologização, ainda na primeira infância.

\section{Considerações finais}

Os projetos educativos englobam as estratégias educativas da família, os estilos parentais e as práticas educativas que os pais lançam mão de forma a concretizar o projeto pensado para os filhos. Fazendo parte disso, o projeto de ensino escolar, pela via da educação formal, o que envolve direitos básicos como acesso à boa educação, entende a escola enquanto um ambiente que propicia o processo de aprendizado e o educador como um ator social participante.

Diante disso, o contexto em que crianças negras e brancas estão inseridas foi apresentado, buscando compreender os papéis exercidos pela família e pela escola na socialização dos infantes. No que se refere ao Brasil, estão presentes na sociedade características raciais que 
OZÓRIO, Claudina Damasceno; PESSÔA, Luciana Fontes. Projetos educativos, crianças negras e socialização: quais diálogos são possíveis?

atravessarão esse processo, colocando-as em situações em que ainda não possuem autonomia e nem gerência para responderem. Conforme os estudos apresentados, foi possível perceber que o silêncio, tanto do lar quanto da escola, reforça o lugar social esperado para brancos e negros, hierarquizando-os em superior e inferior, respectivamente. As consequências são diversas para as crianças negras, como o medo, as humilhações, a dificuldade de formar uma identidade positiva, a baixa autoestima e o autoconceito negativo.

Diante disso, quais diálogos são possíveis de se estabelecer entre os microssistemas familiar e escolar, de forma que possam promover bem-estar e uma educação que rompa com a lógica da violência racial? Se o silêncio ainda impera nesses espaços, como pode-se visibilizar as sutilezas presentes nas relações raciais que são promotoras de violência, tornando possível o diálogo sobre essa temática. 


\section{Referências bibliográficas}

ABRAMOWICZ, A.; OLIVEIRA, F. As relações étnico-raciais e a sociologia da infância no Brasil: alguns aportes. In: BENTO, M. A. S. (Org.). Educação infantil, igualdade racial e diversidades: aspectos políticos, jurídicos, conceituais. São Paulo: Centro de Estudos das Relações de Trabalho e Desigualdades - CEERT, 2012. p. 47-64.

BARBOSA, I. M. F. Socialização e relações raciais: um estudo de família negra em Campinas. São Paulo: FFLCH/ USP, 1983.Antropologia 5.

BERGER, P. L.; LUCKMANN, T. A construção social da realidade. 3.ed. Petrópolis: Vozes, 1976.

CAVAllEIRO, E. S. O Processo de Socialização na Educação infantil: A Construção do Silêncio e da Submissão. Rev. Bras. Cresc. Desenv. Hum., São Paulo, v. 9, n. 2, 1999.

CHAGAS, R. S. A união faz a força: expressões do mito familiar em famílias negras. São Paulo: Intermeios, 2014.

FANON, F. Pele negra, máscaras brancas. Trad. Renato da Silveira. Salvador: Edufba, 2008.

FREYRE, G. Casa grande e senzala. 51.ed., São Paulo: Global, 2006.

HORDGE-FREEMAN, E. A cor do amor: características raciais, estigma e socialização em famílias negras brasileiras. Trad. Victor Hugo Kebbe. São Paulo: EdUFSCar, 2019.

KELLER, H. Diferentes Caminhos de Socialização até a Adolescência. Rev. Bras. Cresc. Desenv. Hum., São Paulo, v. 8, n. 1/2, 1998.

PINHO, O. Etnografia e emancipação: descolonizando a antropologia na escola pública. In: BERNADINO-COSTA, J., MALDONATO-TORRES; GROSFOGUEL, R. (Org.). Decolonialidade e pensamento afrodiaspórico. 2.ed. Belo Horizonte: Autêntica, 2019. Coleção Cultura Negra e Identidades.

SAMARA, E. M. A história da família no Brasil. Revista Brasileira de História, São Paulo, v. 9, n. 17, p. 7-36, set/fev 1988/89. Número especial.

SCHUCMAN, L. V.; GONÇALVES, M. M. Racismo na Família e a Construção da Negritude: Embates e Limites entre a Degradação e a Positivação na Constituição do Sujeito. Odeere (UESB), v. 2, n. 4, p. 61-83, dez 2017.

SCHUCMAN, L. V. Famílias inter-raciais: tensões entre cor e amor. Salvador: Edufba, 2018

SEIDL-DE-MOURA, M. L.; MENDES, D. M. L. F; PESSÔA, L. F. (Orgs.). Interação Social e Desenvolvimento. Curitiba: CRV, 2009.

SLENES, R. W. Na senzala uma flor: esperanças e recordações na formação da família escrava. 2 ed. Campinas: Editora Unicamp, 2011. 
OZÓRIO, Claudina Damasceno; PESSÔA, Luciana Fontes. Projetos educativos, crianças negras e socialização: quais diálogos são possíveis?

WAGNER, A.; TRONCO, C. B.; GONÇALVES, J. S.; DEMARCHI, K. A.; LEVANDOWSKI, D. C. Projetos para os filhos e estratégias de socialização: a perspectiva de pais e mães. Psicologia \& Sociedade, v. 24, n.1, p.122-129, 2012. 